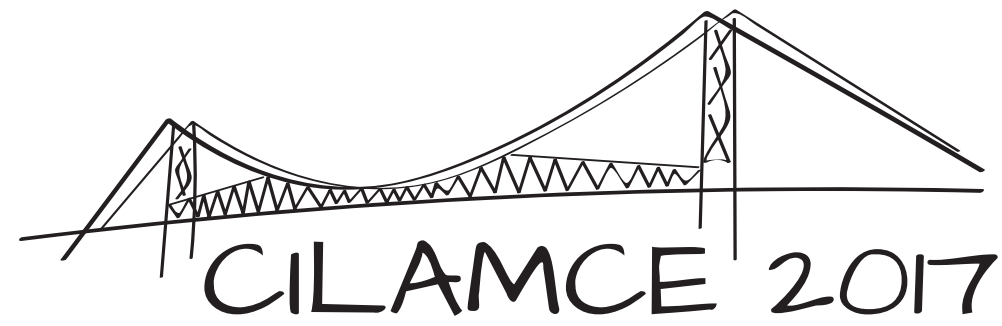

Florianópolis - Santa Catarina - Brazil

\title{
CROSS-SECTION OPTIMIZATION OF CONCRETE GRAVITY DAMS USING GENETIC ALGORITHMS
}

\section{Leilson Joaquim Araújo ${ }^{\dagger}$}

\section{Agno Alves Vieira ${ }^{\ddagger}$}

†leilsonjoaquim@gmail.com

$\ddagger$ agno.vieira@ifg.edu.br

${ }^{\dagger, \ddagger}$ Federal Institute of Education, Sciense and Tecnology of Goiás

Street 64 corner street 11 - Parque Lago, 73813-816, Formosa, Goiás, Brazil

\begin{abstract}
Concrete gravity dams are the most commonly used hydraulic structures in engineering, for the designer these structures, the overall stability (external forces) must be guaranteed as well as the internal stresses that element is subjected to. The scaling mechanisms these structures are presented in the manual Critérios de Projeto Civil de Usinas Hidroelétricas (2003) from Eletrobras, which is strongly influenced by the U.S. Bureau of Reclamation (1976). After an analysis of the proposed design forms, it was observed a tendency to oversize these structures, in order to reduce this oversizing and to obtain slender forms of dam, the present work brings an optimization study for the cross sections of concrete gravity dams, this optimization will be made by means of routines used in Matlab software, the genetic algorithm technique will be used to reduce the cross-section of this type of dam and consequently reduce the volume of concrete used in its construction.
\end{abstract}

Keywords: Optimization, Gravity dams, Cross sections, Genetic algorithm 


\section{INTRODUCTION}

[?] A concrete gravity dam is a structure that acquire stability by her own weight. A solid concrete structure so designed and shaped that it weight is sufficient to ensure stability against the effects of all imposed forces (Usace,1995). That dams generally has trapezoidal cross sections (Gutstein et al., 2011).

However, design this structure is not a simple thing. Although the geometry of a gravity dam is very basic, the structural analysis of a such mass concrete structure is relatively complex, duo to the no-linear material behavior and the variety of static and dynamic load acting on the structure (Durieux,2009). For each case of loads there are several possible configurations that satisfy such requirements. Therefore, many solutions are considered acceptable.

The codes, (ICOLD,2003), (USBR,1976) and (Usace,1995) brings the minimum requirements to ensure the stability of concrete gravity dams, both make use factors of safety, in order to guarantee the overall stability. That way, to ensure the massif equilibrium, must be analyzed, the global balance in flotation, toppling and sliding. However, sometimes, in order to guarantee this safety, dam designers make over-sized structures that produce excessive use of concrete.

In the current context costs and material's reduction is a priority. One way to reduce costs and material's reductions is make optimal design (Vianna, 2003), that is, the best design for the structures studied.

Within the optimization techniques, the technique of genetic algorithms created by John Holland (Holland, 1975) and popularized by David Godberg (Goldberg, 1989) gains force in
detriment of others commonly used, this is happening because of facility that tool can solver
problems.
The principle of genetic algorithm (GA) is simple, it follows the evolutionary theory pro-
posed by Charles Darwin, where the fittest individuals within a given population stirvive time, while the less fit individuals will be eliminated (Bastos, 2004).

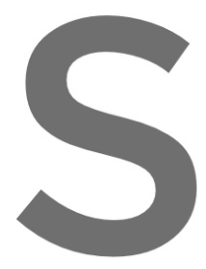

for free at https//www.scipedia.com to download the version without the watermark

It was observed that among the works in area of concrete gravity dams, main focus of in researchers is the stresses suffered in the rocky foundations, having few works focused on the analysis of rigid body.

The purpose of this work is to apply an optimization by genetic algorithms inside the software Matlab, reducing the area of trapezoidal cross sections of concrete gravity dams, consequently reducing the volume of concrete used in the construction of such structures. To elucidate the work efficiency, an example is presented.

\section{METHODS}

The present work makes use of numerical simulations, elaborated in the software Matlab. The research was elaborated from routines in proper language to the software used. However, with due changes, the routines can be applied on other platforms, not being exclusive by Matlab software.

\subsection{Genetic Algorithm}

The main idea of GA follows Darwin's evolution theory, the individuals that better adapt to its environment, will survive and have more offspring. Therefore, the individuals in optimiza- 
tion problems are points of solution, the GA generate a population those (the best solutions), after that, GA modifies population, choosing the individuals more feasible, then, GA repeatedly modifies a population of individual solutions until achieve the best point of solution. (Bastos, 2004).

At each step (iteration), the GA selects individuals at random from the current population to be parents and uses them to produce the children for next generation. Over successive generations, the population evolves toward an optical solution.

As in the evolutionary process of species, genetic algorithms manipulate a population of individuals, each with an associated fitness value, to a new generation of individuals, using the Darwinian principles of reproduction and survival of the fittest, performing genetic selection's operations, crossover and mutation. Each individual of the population in each generation represents a possible solution.

Therefore, basically what the genetic algorithm does, it is to seek from the set of solutions of the search space, always towards the global optimum, the individual with the highest fitness (Bastos, 2004).

The GA can be used to solve problems of unconstrained and constrained optimization. Unconstrained problems consider a problem of minimizing (or maximizing) an objective function that depends on real variable, with no restrictions on their values. Constrained problems of optimization have boundaries that limit their values. In this paper we are treating with a constrained problem (Venkataraman, 2009)

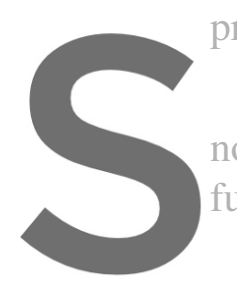

To solve some constrained not enough to solve those proble function.

The penalty function goalis to complex optimization problems, the GA in its simpl
ems. Then, one solution to the is increase GA with
is to convert constrained problems inte unconstraine est form/is ducing an artificial penalty for violating the constraint. The penalty function approach involves

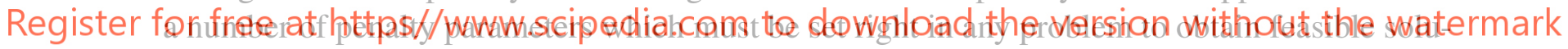
tions (Deb, 2000).

\subsection{Factors of safety}

In order to guarantee the overall stability of a concrete dam, the codes refer to maintaining the equilibrium of dam's rigid body, to have this equilibrium satisfied. It is necessary to guarantee stability of the structure regarding phenomena of to floating, toppling and sliding. Therefore, using a factor of safety for each of those phenomena, might achieve a security design (ICOLD, 2003).

Floating factor of safety $(F S F)$, has the function to guarantee the stability of structure against the forces that tend to make the body float. The floating factor of safety is defined as the ratio between the sum of the forces gravitational forces, and the sum of the forces of underpressure (ICOLD, 2003). The FSF is here calculate using the expression (1).

$$
F S F=\frac{\sum V}{\sum U}
$$


$F S F$ is the floating factor of safety, $\sum V$ is the sum of vertical forces and $\sum U$ is the sum of polypression.

The factor of safety against toppling $(F S T)$, deals with the stability of the structure for the moments to which it is subject. The factor of safety for toppling in any direction is defined as the ratio between the stabilizing moments and the toppling moments, over a point or an effective line of rotation (ICOLD, 2003). FST is here calculate using the expression (2).

$$
F S T=\frac{\sum M e}{\sum M t}
$$

$F S T$ is safety factor against toppling, $\sum M e$ is the sum of stabilizing moments and $\sum M t$ is the sum of toppling moments.

Sliding factor of safety $(F S D)$, guarantees safer margins of structural stability against translational movements. In order to verify the stability of structures to sliding (slip), rupture surfaces should be selected to include all low resistance, or those subjected to critical stresses in the structure, and in the foundation-structure contact on which the dam may suffer sliding movement as rigid body (ICOLD, 2003). The expression for FSD is (3).
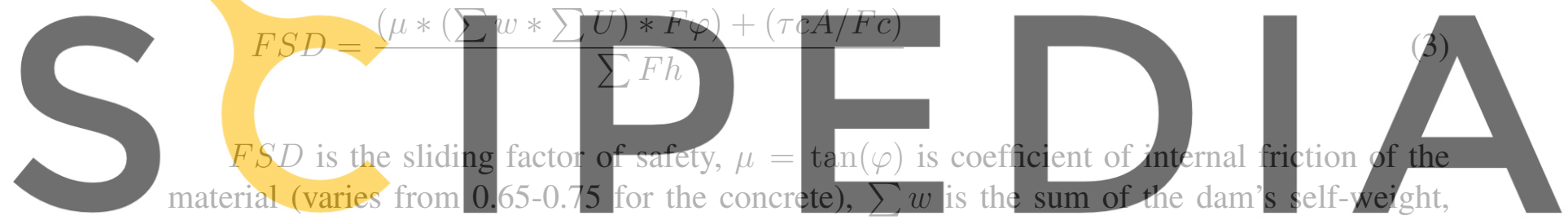

$\sum U$ is the sum of polypression, $F \varphi$ is the partial factor of safety in relation to friction, $\tau c A$

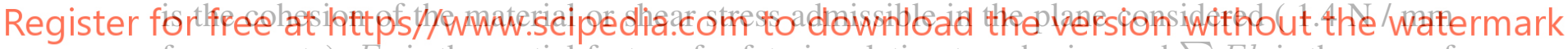
for concrete), $F_{C}$ is the partial factor of safety in relation to cohesion and $\sum F h$ is the sum of horizontal forces.

\subsection{Construction of the problem and the solution}

The problem here studied is the over sizing in design of concrete gravity dams. An explanation for this tendency to oversize, its the nature of the problem, its a great volume of concrete inside the water. Concrete is a non-linear material of difficult prediction, however, those structures have a great size, so that the massif acquire stability by self-weight.

To guarantee the dam security, it's necessary to analyses global stability and the stresses in foundation. Here is studied the process involving global stability of the dams. The stresses in foundation are not studied here, there are many works who analyzed that, such as (Gutstein, 2003), (Gutstein, 2011), (Ribeiro, 2006), (Araujo, 2005).

To guarantee the global stability of a concrete gravity dams, have to be reached, values for the factors of safety higher than the minimum required by design standards. In this way, considering normal loading conditions, the values for factors of safety are 1.3 for $F S F, 1.5$ for $F S T$ and 1 for FSD (ICOLD, 2003). 


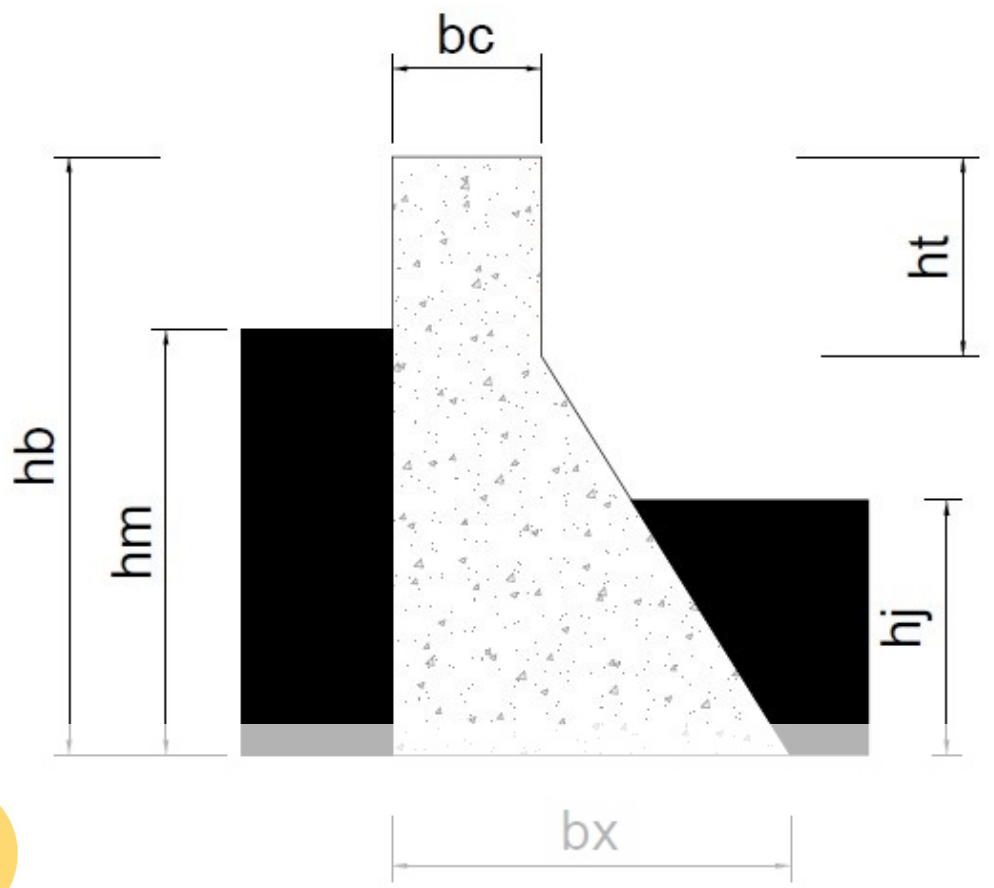

Figure 1: Generic scheme of the studied cross section

In order to calculate the overall stability of the structure, a main routine was developed serving as a starting point for the entire study. This routine calculate body equilibrium of the dam from conditions provided by the designer. This algorith safety, calculated by (1), (2) and (3) from the arrangement that

Using the genetid a gorithm option that Matiab brings, it mechanism for the cross-sections of the dams. It consists of a discretization of the problem in

Register for free at https//www.scipedia.com to download the version without the watermark

First, an objective function was defined, that is, the function to be optimized or just fitness function. This fitness function refers to the cross-sectional area of a concrete gravity dam, resembling the area of a trapezoid, the function is shown in equation 4.

$$
f(A)=(h b * b c)+\frac{(b x-b c) *(h b-h t)}{2}
$$

$A$ is the cross-section area of the dam, $f(A)$ is the function that represent the area of the dam, $h b$ is the height of the dam, $b x$ width of the dam, $b c$ is width of the dam crest and $h t$ is tardoz height. Other two inherent parameters upstream $h \mathrm{~m}$ and downstream water column $h j$ were defined. The parameters are illustrated in scheme of figure 1.

To calculate the effects, on which the dam is subject, it was necessary to define some constants. These constants are shown in table 1.

Defining the function to be optimized, we proceeded to delimit the constrained conditions. So that, calculating $F S F$ (eq. 1), FST (eq. 2) e $F S D$ (eq. 3), the constraints are defined equations (5), (6) and (7).

$$
1.3-F S F \leq 0
$$


Table 1: Constants adopted

\begin{tabular}{ccc}
\hline Constant & Nomenclature & Value \\
\hline Specific weight of water & $\gamma w$ & $10\left(\mathrm{kN} / \mathrm{m}^{3}\right)$ \\
Specific weight of concrete & $\gamma c$ & $25\left(\mathrm{kN} / \mathrm{m}^{3}\right)$ \\
Saturated soil specific weight & $\gamma s a t$ & $20\left(\mathrm{kN} / \mathrm{m}^{3}\right)$ \\
Dry weight specific weight & $\gamma s a t$ & $18\left(\mathrm{kN} / \mathrm{m}^{3}\right)$ \\
Concrete-rock mean cohesion & $C r$ & $800\left(k N / \mathrm{m}^{2}\right)$ \\
Rock friction angle & $\varphi r$ & $\frac{\Pi}{4}$ \\
Partial friction safety factor & $f a t$ & 1 \\
Internal friction coefficient & $A$ & 0.7
\end{tabular}

Having the objective function and the constraints, the optimization was performed with the GA. The GA
defined (eq. 8).
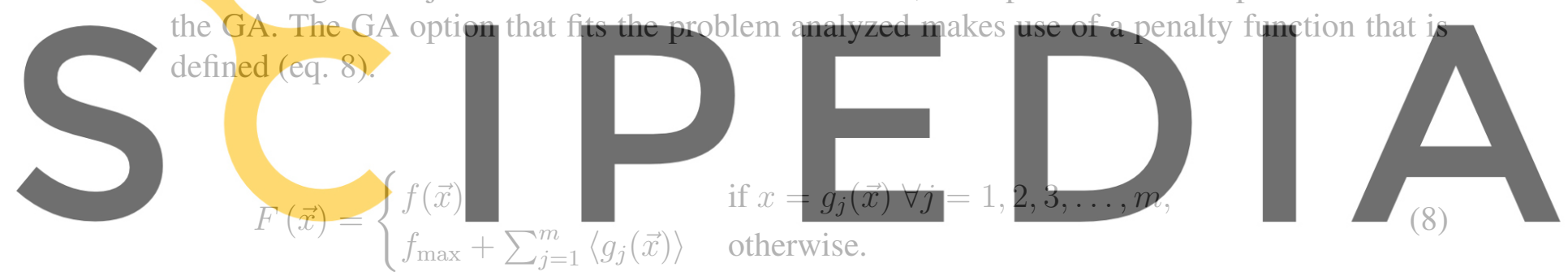

Register for free at https//www.scipedia.com to download the version without the watermark

This penalty function combined with binary tournament selection to select individual for subsequent generation. The $F(x)$ of a population's member is $f(x)$ if the member is feasibie. Whether the the member is infeasible, the $F \overrightarrow{(x)}$ is the maximum fitness function, fmax, among feasible member of the population plus the sum of the constraint violation of the point $\sum_{j=1}^{m} g i$ (Chipperfield, 1995). If no feasible solution exists in a population, fmax is set to zero (Deb, 2000).

With the fitness function programed inside a script, the constraint in other one, already can optimize the section of interest. To do that, it is necessary to define the other parameters to feed the GA.

Within the parameters, the dimensions of the analyzed dam will be included, and the measurements determined in the pre-demise will be used as maximum border values for the studied function.

The designer must arbitrate lower dimensions for the dam, those must follow the logic of the problem studied. For example, the height of the dam must satisfy the maxi maximorum. With the defined lower boundaries, the GA will work within the range of these lower boundaries and the dimensions defined in the pre-dimensioning. 


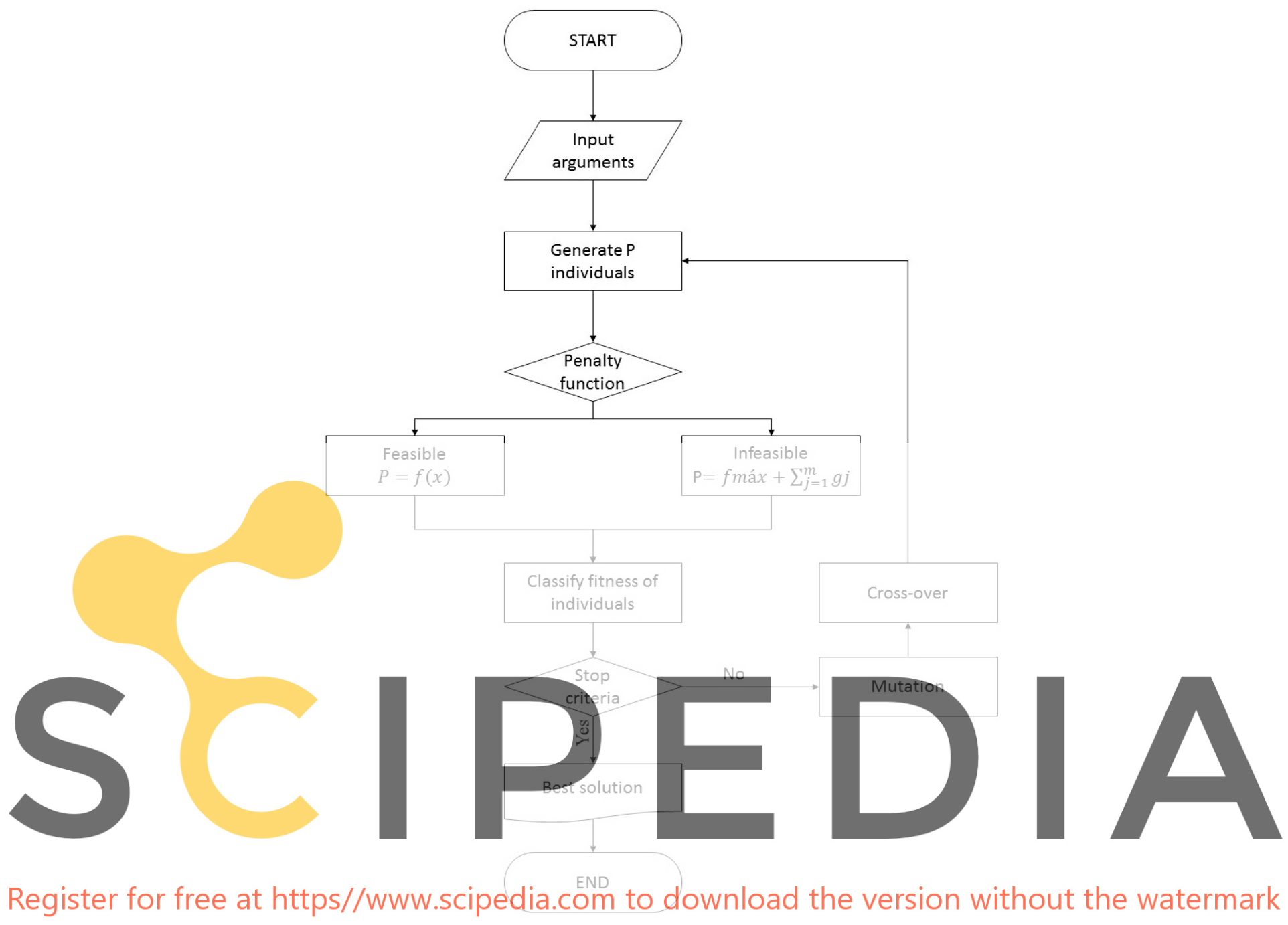

Figure 2: Genetic algorithm functioning

With the dimensions of the dam already defined. One of the dimensions is arbitrated as integer variable. In figure 2 is presented the operation of optimization routine.

\section{EXAMPLE}

In order to demonstrate what the cross-sectional optimization can do for the best design of a concrete gravity dam, a example has been defined to be studied, this example treats a hypothetical dam that follows the molds of conventional dam structural designs.

The (Usace, 1995) as well as other bibliographies diffused worldwide, recommend the width of the dam $b x$ as being about 0.7 of the height of the dam $h b$ (Gutstein, 2003), aiming at the initial sizing case follows this recommendation, as well as another widespread recommendation in which the dam crust $b c$ is about 0.3 from the width of the dam $b x$. 
Table 2: Initial dimensions of the dam

\begin{tabular}{ccc}
\hline Study range & Nomenclature & Value \\
\hline Area of the dam & $A$ & $4182.5\left(\mathrm{~m}^{2}\right)$ \\
Height of the dam & $h b$ & $100(\mathrm{~m})$ \\
Width of the dam & $b x$ & $70(\mathrm{~m})$ \\
Dam crest & $b c$ & $21(\mathrm{~m})$ \\
Tardoz height & $h t$ & $15(\mathrm{~m})$ \\
Upstream water & $h m$ & $90(\mathrm{~m})$ \\
Downstream water & $h j$ & $60(\mathrm{~m})$ \\
Factor of safety Float & FSF & 1.9785 \\
Factor of safety toppling & FST & 1.6191 \\
Factor of safety sliding & FSD & 1.5982 \\
\hline & & \\
\hline
\end{tabular}

Register for free at https//www.scipedia.cón to to download the version without the watermark

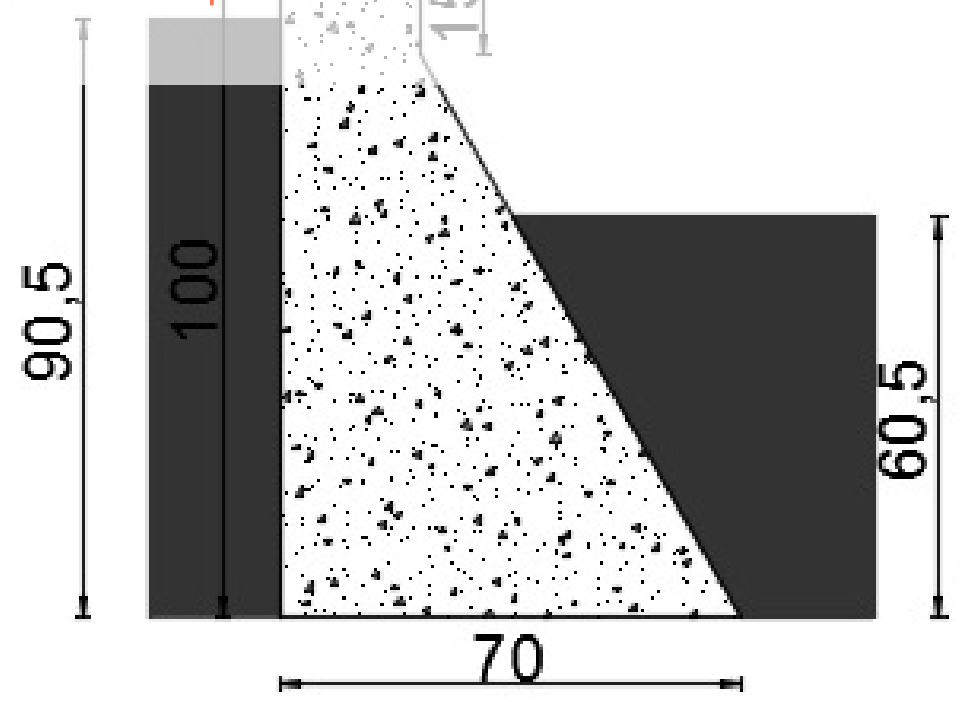

Figure 3: Initial dimensions of the dam 
Table 3: Parameters of the GA

\begin{tabular}{cc}
\hline Parameter & Adopted \\
\hline Population type & Double vector \\
Population size & $10^{3}$ \\
Maximum number of iterations & $10^{2}$ \\
Function tolerance & $10^{-6}$ \\
Cross-over fraction & 0.8 \\
Mutation function & Constraint dependent \\
Cross-over function & Constraint dependent \\
Migration direction & Forward \\
Migration fraction & 0.2 \\
Migration interval & 20 \\
Code & Real \\
\hline
\end{tabular}

To make the optimization bounder of the GA, and $93(m), b x=50(m)$, GA operation it is necess in table 3 .
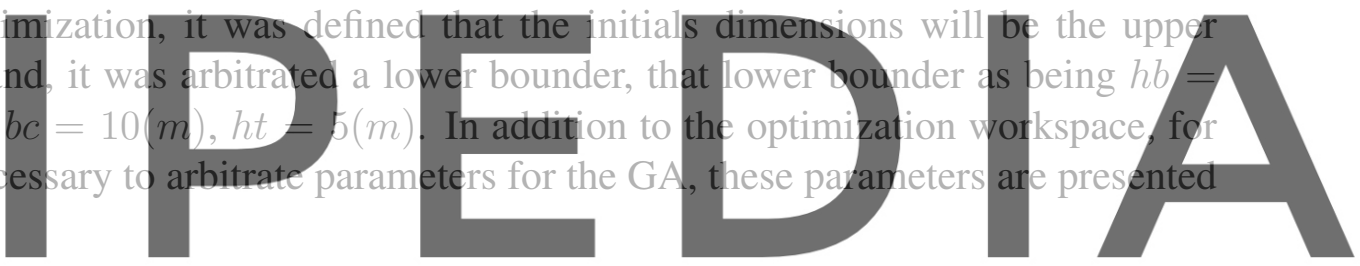

Finally, optimization of dam's cross-section might be performed. However, it was defined

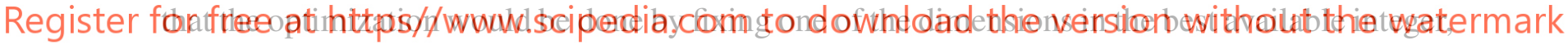
that value being chosen by GA, making the other parameters vary successively until the desired optimum section is obtained. Thus, an optimization was performed for each of the four dimensions of the dam, these results will be presented separately. The stop criteria is the number of iterations (100).

\subsection{Optimization}

In the process of sections's optimization, it was adopted as a constant one dimension in relation to the others, so that, in the first optimized section, the height of the dam was fixed, followed by width, crest and tardoz.

First it was analyzed the behavior that the function area presents within GA, that way, can be analyzed the how that the choice of the dimension to be fixed implies in the form of convergence. The behavior for the different optimization options adopted is presented in figures $4,5,6$ and 7.

Graphs (a) in figures 4, 5, 6 and 7, it shows the best penalty function found in each iteration, besides, it shows the mean values for the penalty functions for each of the iterations.

Can be observed that the best values found, in all cases, already presents in the first inter- 

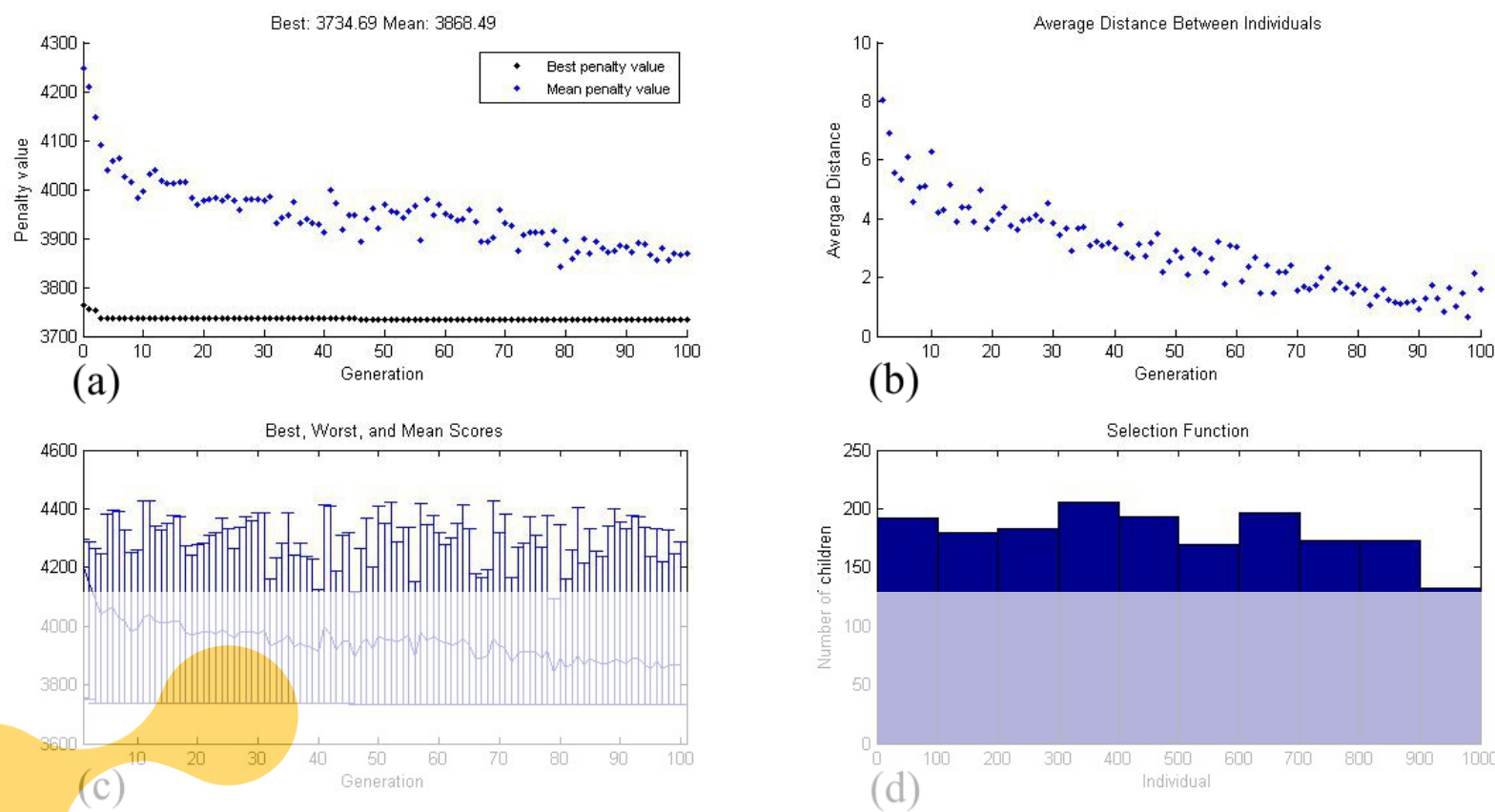

Figure 4: Optimum section-fixed height
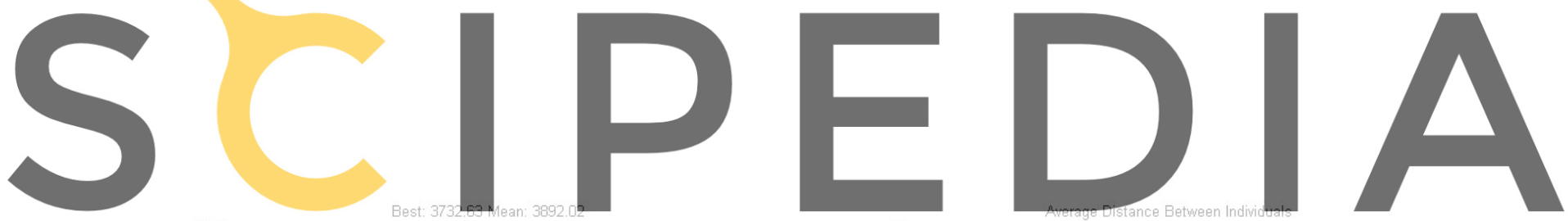

Register for free at https//www.scipedia.com to download the version without the watermark

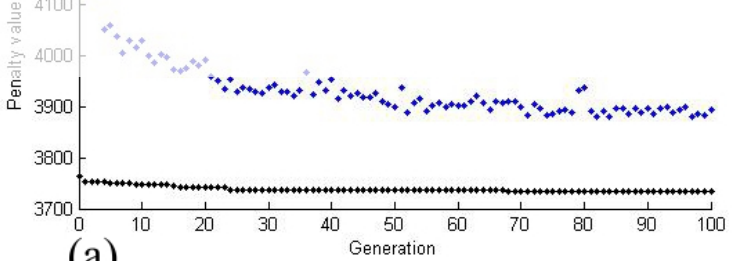

(a)
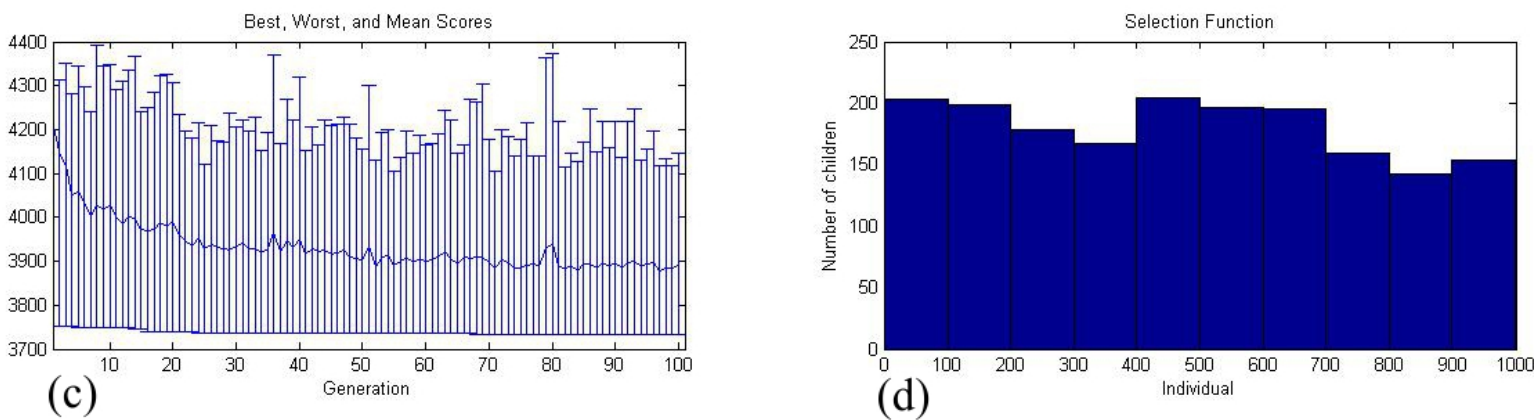

Figure 5: Optimum section-fixed Width 

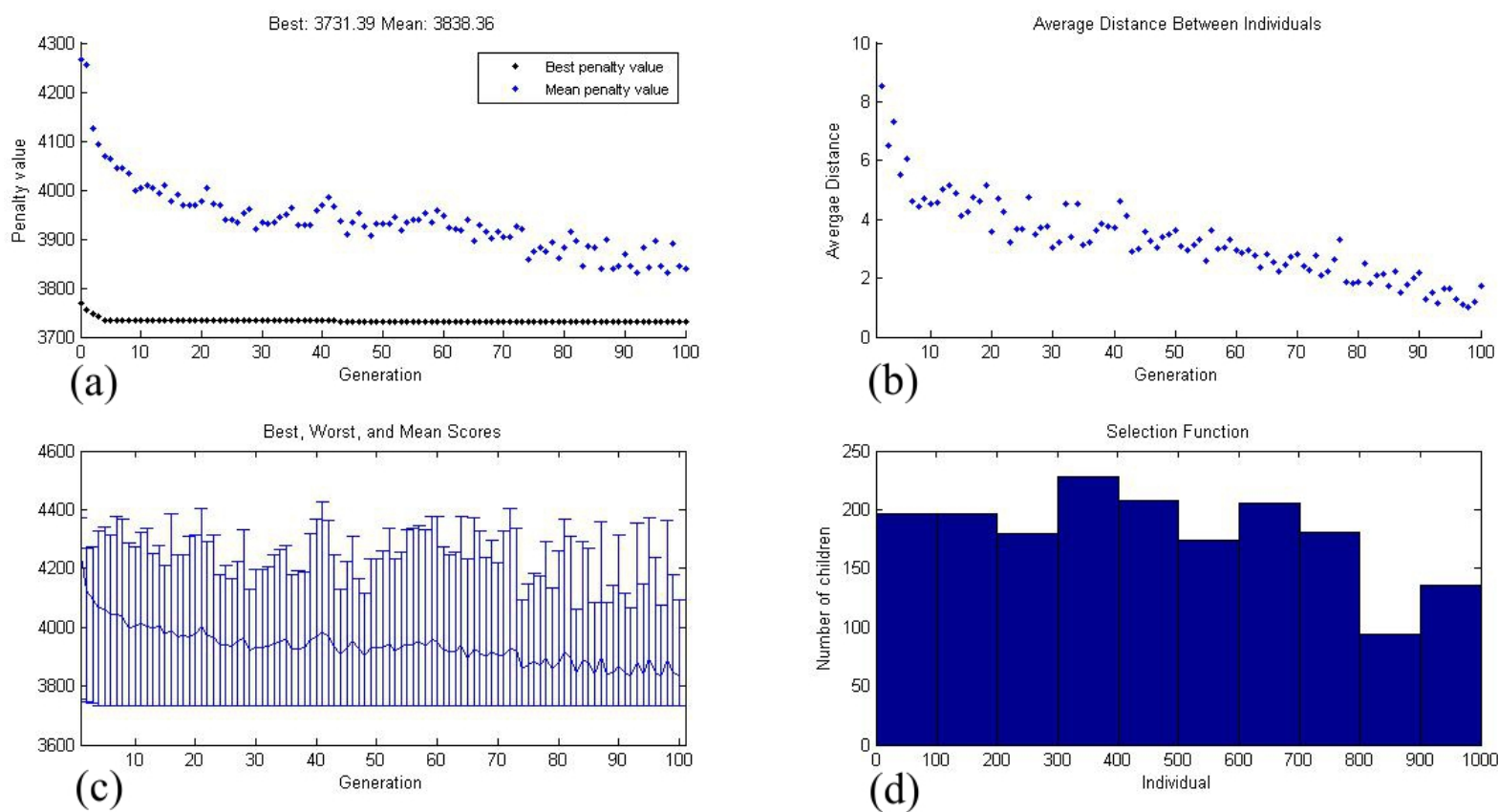

Figure 6: Optimum section-fixed Crest
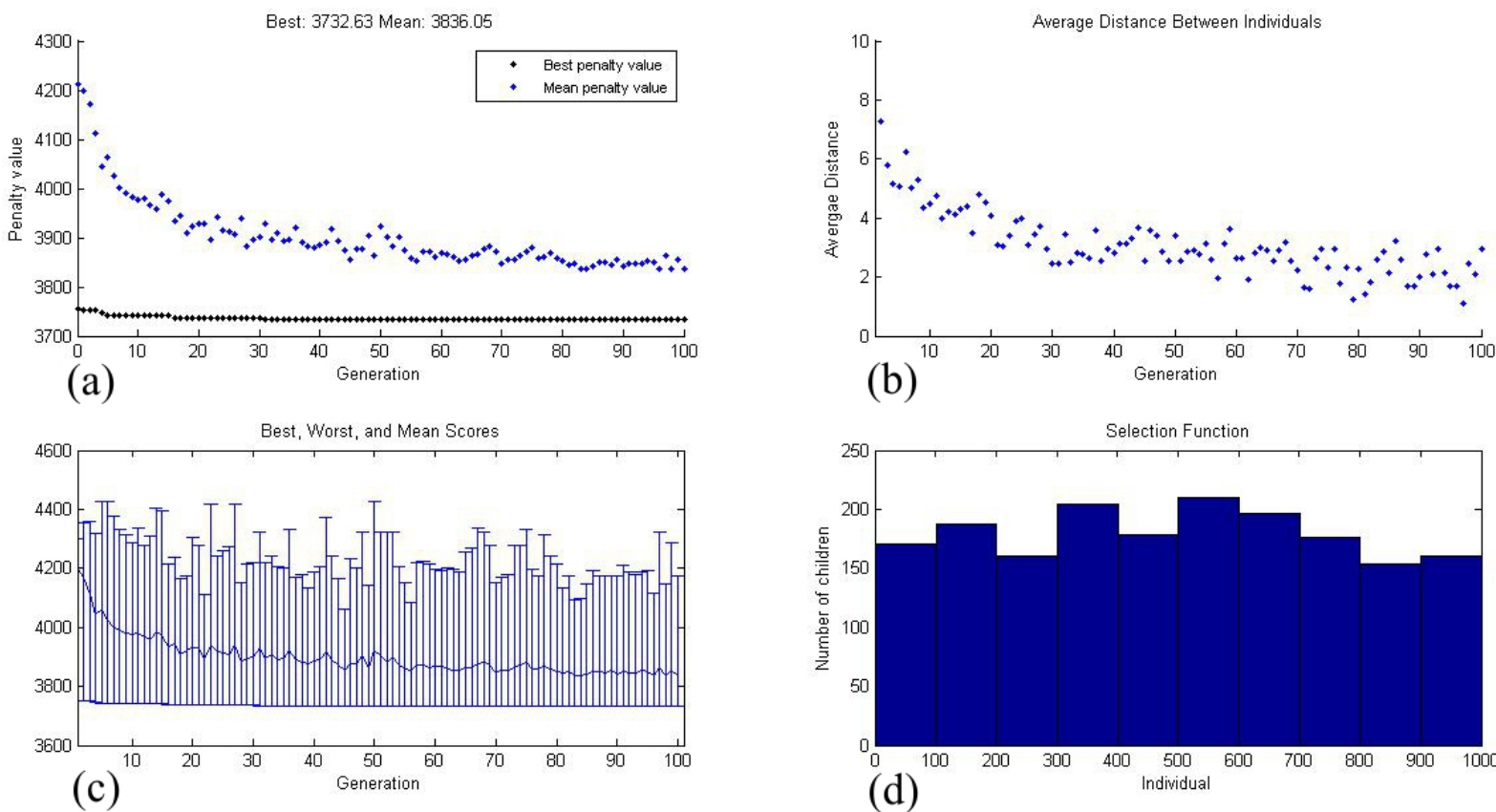

Figure 7: Optimum section-fixed Tardoz 
Table 4: Optimum section-fixed height

\begin{tabular}{ccc}
\hline Study range & Nomenclature & Value \\
\hline Area of the dam & $A$ & $3734.7\left(\mathrm{~m}^{2}\right)$ \\
Height of the dam & $h b$ & $100(\mathrm{~m})$ \\
Width of the dam & $b x$ & $63.5279(\mathrm{~m})$ \\
Dam crest & $b c$ & $17.7846(\mathrm{~m})$ \\
Tardoz height & $h t$ & $14.4693(\mathrm{~m})$ \\
Upstream water & $h m$ & $90(\mathrm{~m})$ \\
Downstream water & $h j$ & $60(\mathrm{~m})$ \\
Factor of safety Float & $F S F$ & 1.9466 \\
Factor of safety toppling & $F S T$ & 1.5000 \\
Factor of safety sliding & $F S D$ & 1.4032 \\
\hline
\end{tabular}

action, values that bring savings of satisfactory area. However, the mean values show values distant to those expected by the algorithm.

In the graphs (b), in figures $4,5,6$ and 7, the distances between the individuals are analyzed, in these graphs it was evidenced a tendency that when the width of the dam is fixed, the individuals tend to be closer in the future generations.

The other three optimizations are closely similar, given that there is a similar medium distance. It can be concluded that by this configuration, when fixing the width of the dam the GA tends to converge faster in relation to the other proposals.

Graphs (c) in figures 4, 5, 6 and 7, show a comparison between the worst, the best and the average values obtained. It should be noted that in all cases analyzed, the best values are far from the worst ones, which shows even more the advantage of optimizing a project. Since even the mean values found are far from the desired values.

In graphs (d) in figures 4, 5, 6 and 7, the behavior that the cross-over brings to as different variants of optimization are analyzed, being that all the configurations presented a procreation condition very close to each other. The results of the dimensions optimized are presented in the tables 4, 5, 6 and 7 .

it was observed that the choice of dimension to be fixed, in terms of area savings, implies little in the results obtained.

Thus, it is up to the designer choose which of the dimensions will be fixed, in search of the optimum section that best suits your case. This choice may be influenced by external factors, such as a topographical configuration of the terrain or climatic conditions of the region.

To better observe the economy that optimization offers, in figure 9 a scheme is presented, in this scheme the optimized section is materialized inside the initial. 
Table 5: Optimum section-fixed Width

\begin{tabular}{ccc}
\hline Study range & Nomenclature & Value \\
\hline Area of the dam & $A$ & $3732.6\left(\mathrm{~m}^{2}\right)$ \\
Height of the dam & $h b$ & $99.7039(\mathrm{~m})$ \\
Width of the dam & $b x$ & $62(\mathrm{~m})$ \\
Dam crest & $b c$ & $19.1937(\mathrm{~m})$ \\
Tardoz height & $h t$ & $14.7190(\mathrm{~m})$ \\
Upstream water & $h m$ & $90(\mathrm{~m})$ \\
Downstream water & $h j$ & $60(\mathrm{~m})$ \\
Factor of safety Float & $F S F$ & 1.9935 \\
Factor of safety toppling & $F S T$ & 1.5000 \\
Factor of safety sliding & $F S D$ & 1.4373 \\
\hline
\end{tabular}

Table 6: Optimum section-fixed Crest

\begin{tabular}{ccc}
\hline Study range & Nomenclature & Value \\
\hline Area of the dam & $A$ & $3731.4\left(\mathrm{~m}^{2}\right)$ \\
Height of the dam & $h b$ & $99.9113(\mathrm{~m})$ \\
Width of the dam & $b x$ & $61.8585(\mathrm{~m})$ \\
Dam crest & $b c$ & $19(\mathrm{~m})$ \\
Tardoz height & $h t$ & $14.3700(\mathrm{~m})$ \\
Upstream water & $h m$ & $90(\mathrm{~m})$ \\
Downstream water & $h j$ & $60(\mathrm{~m})$ \\
Factor of safety Float & $F S F$ & 1.9974 \\
Factor of safety toppling & $F S T$ & 1.5000 \\
Factor of safety sliding & $F S D$ & 1.4396 \\
\hline
\end{tabular}


Table 7: Optimum section-fixed Tardoz height

\begin{tabular}{ccc}
\hline Study range & Nomenclature & Value \\
\hline Area of the dam & $A$ & $3732.6\left(\mathrm{~m}^{2}\right)$ \\
Height of the dam & $h b$ & $99.9965(\mathrm{~m})$ \\
Width of the dam & $b x$ & $62.2791(\mathrm{~m})$ \\
Dam crest & $b c$ & $18.5047(\mathrm{~m})$ \\
Tardoz height & $h t$ & $14(\mathrm{~m})$ \\
Upstream water & $h m$ & $90(\mathrm{~m})$ \\
Downstream water & $h j$ & $60(\mathrm{~m})$ \\
Factor of safety Float & $F S F$ & 1.9846 \\
Factor of safety toppling & $F S T$ & 1.5000 \\
Factor of safety sliding & $F S D$ & 1.4307 \\
\hline
\end{tabular}

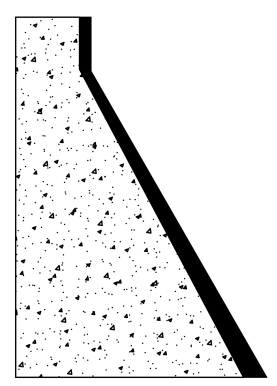

Height fixed

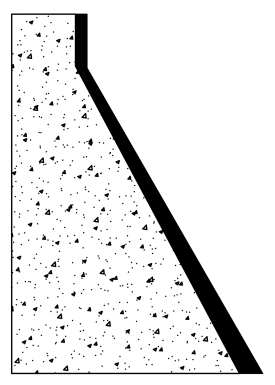

Height fixed

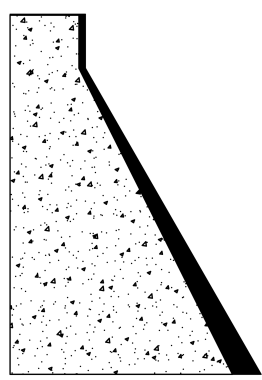

Figure 8: Cross-sections optimized

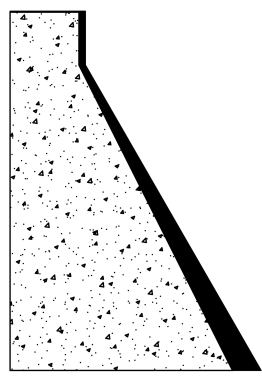

Figure 9: Cross-sections optimized

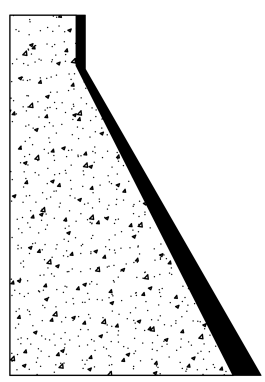

Tardoz fixed

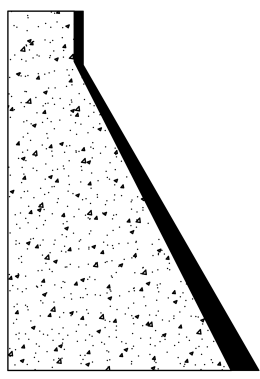

tardoz fixed

A comparison is made between the cases studied. From this comparison, it can be seen how the values obtained are close to each other.

The choice of a section to be fixed makes no difference to the desired result. However, all the optimized sections have a relevant area saving and, consequently, a desirable saving in concrete volume. 


\section{CONCLUSIONS}

The present work brought a methodology cross-section optimization of concrete gravity dams. The process presented here was based on genetic algorithms in Matlab function to produce economic cross-sections.

The genetic technique algorithms proved to be an important ally of the optimization process programming, being able to be applied in different cases and extend to many areas of engineering.

The optimization produced using GA satisfactory results, producing transversal sections with concrete saving about 10 percent. It is observed, how optimization work can bring benefits to concrete economy. Being that, if applied in large scale dams, the saving of concrete can reach thousands of $m^{3}$.

In a design of great magnitude and high complexity such as dam, codes tend to be conservative in favor of safety. However, studies of optimization such as the one presented here show us that we can do more economic designs while maintaining the safety of the structure.

\section{ACKNOWLEDGMENTS}

The authors are very grateful for the help offered by their friend Marcelo L. Pereira Júnior. Comments made by Wallison Barbosa. Some parts of this study were made during the research in which the authors are inserted, because of this, the authors thank the IFG teaching institution.

\section{REFERENCES}

E. A. Bastos. Otimizaoao de sees retangulares de concreto armado submetidas flexo compresso oblqua utilizando algoritmos genticos. Rio de Janeiro, 2004.

N. Benevolo. Diretrizes para o projeto de grandes barragens de concreto. 1973.

A. Chipperfield and P. Fleming. The matlab genetic algorithm toolbox. 1995.

K. Deb. An efficient constraint handling method for genetic algorithms. Computer methods in applied mechanics and engineering, 186(2):311?338, 2000.

J. H. Durieux. Development of a practical methodology for the analysis of gravity dams using the non-linear finite element method. PhD thesis, University of Pretoria, 2009.

D. Gutstein. Projeto de estruturas de barragens de gravidade de concreto por meio de mtodos computacionais: Viso Geral e Metodologia. page 303, 2011.

D. Gutstein et al. Estudo das tenses em fundaes de barragens de gravidade de concreto pelo mtodo de elementos finitos. 2003.

ICOLD. Criterios de Projeto Civil de Usinas Hidreltricas.. Centrais Eltricas Bras. S.A. ELETROBRS, page 279, 2003.

Usace. Gravity Dam Design. USACE Eng. Man., (June):88, 1995.

USBR. Design of gravity dams. 1976

P. Venkataraman. Applied optimization with MATLAB programming. John Wiley e Sons, 2009. 
L. C. C. Vianna. Otimizao de sees transversais de concreto armado: aplicao a prticos. PhD thesis, Universidade de S?ao Paulo, 2003. 